\title{
ANALOG COMPUTING FOR A NEW NUCLEAR REACTOR DYNAMIC MODEL BASED ON A TIME-DEPENDENT SECOND ORDER FORM OF THE NEUTRON TRANSPORT EQUATION
}

\author{
AHMAD PIROUZMAND ${ }^{\mathrm{a}, \mathrm{b}^{*}}, \mathrm{KAMAL} \mathrm{HADAD}^{\mathrm{a}}$, and KUNE Y. SUH ${ }^{\mathrm{b}}$ \\ ${ }^{a}$ Department of Nuclear Engineering, Shiraz University, Shiraz 7134851154, Iran \\ ${ }^{b}$ Department of Energy Systems Engineering, Seoul National University \\ 599 Gwanak-Ro, Gwanak-Gu, Seoul, 151-744, Korea \\ *Corresponding author. E-mail : pirouzm@shirazu.ac.ir
}

Received September 09, 2010

Accepted for Publication January 12, 2011

This paper considers the concept of analog computing based on a cellular neural network (CNN) paradigm to simulate nuclear reactor dynamics using a time-dependent second order form of the neutron transport equation. Instead of solving nuclear reactor dynamic equations numerically, which is time-consuming and suffers from such weaknesses as vulnerability to transient phenomena, accumulation of round-off errors and floating-point overflows, use is made of a new method based on a cellular neural network. The state-of-the-art shows the $\mathrm{CNN}$ as being an alternative solution to the conventional numerical computation method. Indeed CNN is an analog computing paradigm that performs ultra-fast calculations and provides accurate results. In this study use is made of the CNN model to simulate the space-time response of scalar flux distribution in steady state and transient conditions. The CNN model also is used to simulate step perturbation in the core. The accuracy and capability of the CNN model are examined in 2D Cartesian geometry for two fixed source problems, a mini-BWR assembly, and a TWIGL Seed/Blanket problem. We also use the CNN model concurrently for a typical small PWR assembly to simulate the effect of temperature feedback, poisons, and control rods on the scalar flux distribution.

KEYWORDS : Time-dependent Second Order form of Neutron Transport Equation, Cellular Neural Network, Nuclear Reactor Dynamics, Analog Computing

\section{INTRODUCTION}

Good understanding and prediction of the nuclear reactor dynamics are essential parts of correct system simulation for overall nuclear power plant performance and safety during transients [1-2]. Previous studies have proposed generally simplified models to simulate the reactor kinetics. These models utilize the point kinetics equations for reactor power calculations [3-8]. There are also some works that utilize more accurate models such as the multi-point reactor model, the neutron diffusion equation, and the neutron transport equation [9-11]. However, these models are based on numerical methods that are time-consuming and suffer from such weaknesses as vulnerability to transient phenomena, accumulation of round-off errors and floating-point overflows. This study is a continuation of a previous work in which we effectively simulated the dynamics of a typical nuclear reactor with a semi-analog medium using the neutron diffusion approximation to compute the reactor power distribution [12]. We have now further improved the CNN application with the time-dependent transport equation. In this work, the second-order form of the time-dependent neutron transport equation in two-dimensional (2D) Cartesian geometry, together with one equivalent group of neutron precursor density, temperature feedback, and neutron poisons consisting of xenon and iodine equations, are used to evaluate the scalar flux distribution in the core during the steady state and transient in operation. The feedback reactivity dynamic model is described in terms of fuel and coolant temperature changes handled properly using a feedback reactivity coefficient. Instead of solving these equations numerically, use is made of a new method based on the cellular neural network. The CNN method has great potential to efficiently analyze complex and stiff models and provide ultra-fast and accurate solutions [13-17]. The CNN model, which is an equivalent electrical circuit, is used to simulate a space-time response of scalar flux in the steady state and transient conditions. The CNN results are compared against three benchmark problems in 2D Cartesian geometry. Use is made of the CNN model to simulate step perturbation in the core. The accuracy and capability of the CNN model are examined in 2D Cartesian geometry for two fixed source problems, a mini-BWR 
assembly, and a TWIGL Seed/Blanket problem. Finally, we use the CNN model for a typical small PWR assembly to simulate the effect of temperature feedback, poisons, and control rods on scalar flux distribution.

The advantages of the CNN simulator over numerical methods have to do with its analog and parallel processing algorithm. They include, but are not necessarily limited to, reduction in the computational time, circumvention of the exponential increase in complexity as the scale and dimension of problems increase, and the capability of modeling transient conditions. The $\mathrm{CNN}$ model, being an online and real-time system, can simulate the effect of system parameter variations during simulation.

CNN can be implemented by VLSI (Very LargeScale Integrated) technology or emulated by FPGA (Field Programmable Gate Array), so the solving time is drastically reduced compared to solving by simulation on a PC. Some authors have tried to show the capability of $\mathrm{CNN}$ in reducing the computational time by implementing the CNN using FPGA. The simulation of two-dimensional compressible flow on emulated digital CNN-UM was studied by Sandor Kocsardi et al. [18]. They used FPGA implementation of emulated digital CNN to improve the performance of their solution. The properties of the implemented specialized architecture were examined in terms of area, speed and accuracy. Results show that an order of 21-time speedup could be achieved compared to Intel Core2Duo T7200 processor running on $2 \mathrm{GHz}$. In another work, a multilayer discrete time CNN simulator of the heat equation implemented on an FPGA was presented [19]. The FPGA implementation acting as a hardware accelerator was used to reduce the excessive computing time by a factor of 34 .

\section{THEORY}

\subsection{Architecture of CNN}

The basic unit of a CNN is called a cell. It contains linear and nonlinear circuit elements that typically are capacitors, resistors, controlled sources and an independent source. The structure of a two-dimensional (2D) $3 \times 3$ $\mathrm{CNN}$ is shown in Fig. 1.

Consider an $M \times N$ cellular neural network, having $M$ rows and $N$ columns. We call the cell on the $i^{\text {th }}$ row and $j^{\text {th }}$ column cell $(i, j)$ and denote it as $C(i, j)$.

The cell architecture has been discussed thoroughly in previous studies [12], [20]. However we now modify the equivalent electrical circuit of each cell to model the second order form of the time-dependent neutron transport equation using CNN. Fig. 2 shows a new cell electrical circuit where the suffixes $x, d, e$ and $y$ denote the state, differentiator input, differentiator output and cell output, respectively. The node voltage $v_{x i j}$ of $C(i, j)$ is defined as the state of the cell. The node voltage $v_{y i j}$ is called the output of $C(i, j)$.
We can observe in Fig. 2(a) that each cell contains one independent current source, one linear-capacitor $C$, three linear resistors $R_{x}, R_{e}$ and $R_{y}$, one linear voltagecontrolled voltage source, a Second Order Differentiator (SOD) and linear voltage-controlled current sources, which are coupled to neighboring cells via the feedback from the output voltage $v_{y i j^{\prime}}$ of each neighbor cell $C\left(i^{\prime}, j^{\prime}\right)$.

Particularly, $I_{x y L}\left(i, j: i^{\prime}, j^{\prime}\right)$ (with $\left.L=1,2, \ldots k\right)$ are linear voltage-controlled current sources with the characteristics $I_{x y L}\left(i, j: i^{\prime}, j^{\prime}\right)=A_{L}\left(i, j: i^{\prime}, j^{\prime}\right) \cdot v_{y i^{\prime} j^{\prime}}$ for which $A_{L}\left(i, j: i^{\prime}, j^{\prime}\right)$ is the output feedback from cell $\left(i^{\prime}, j^{\prime}\right)$ to cell $(i, j), I_{x e}(i, j: i, j)$ is a linear voltage-controlled current source with the characteristics $I_{x e}(i, j: i, j)=v_{e i j} ; V_{d x}(i, j: i, j)$ is a linear voltage-controlled voltage source with the characteristics $V_{d x}(i, j: i, j)=D_{\text {gain }} . v_{x i j} ; S O D$ is a second order differentiator with the characteristic $v_{e i j}=-d^{2} v_{d i j} / d^{2} t$; an electrical circuit is shown in Fig. 2(b); and $I_{y x}(i, j: i, j)$ is a piecewise-linear voltage-controlled current source, $I_{y x}=\left(1 / R_{y}\right) f\left(v_{x i j}\right)$, with characteristic $f(\cdot)$, as shown in Fig. 3.

The second-order nonlinear differential equation defining the dynamics of each cell can be derived as follows:

State equation:

$$
\begin{aligned}
C \frac{d v_{x i j}}{d t}= & -\frac{1}{R_{x}} v_{x i j}+\sum_{C(k, l) \in N_{r}(i, j)} A(i, j: k, l) v_{y i j} \\
& +I_{S}-D_{\text {gain }} \frac{d^{2} v_{x i j}}{d^{2} t}, 1 \leq i \leq M, 1 \leq j \leq N
\end{aligned}
$$

\section{Output equation:}

$$
v_{y i j}=\left\{\begin{array}{l}
V_{o}, \quad v_{x i j} \geq V_{o} \\
v_{x i j}, \quad 0 \leq v_{x i j} \leq V_{o} \\
0, \quad \text { Otherwise }
\end{array}\right.
$$

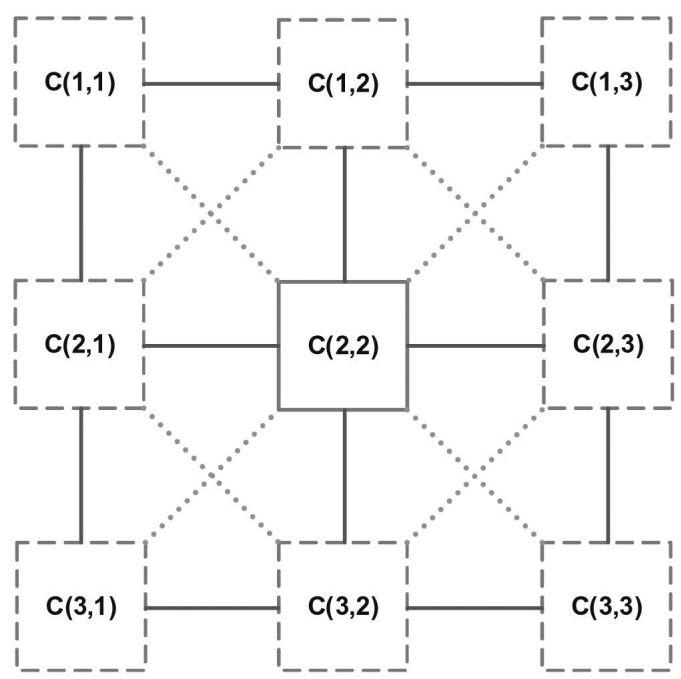

Fig. 1. A 2D Cellular Neural Network of Size $3 \times 3$. Squares are the Circuit Units Called Cells. Links Between Cells Indicate Interactions Between Them. 


\subsection{Reactor Core Dynamic Equations}

Reactor core dynamics are represented by linear and nonlinear differential equations with varying coefficients, which are functions of the core operating conditions (power level, coolant and fuel temperatures, coolant density, poison buildup, burn-up rate, etc.)[21]. In this study we used a dynamic model based on the neutron transport equation with the following assumptions:

- Spherical Harmonic expansion for angular dependency of neutron transport equation.

- Multi-group approximation for energy domain.

- One equivalent group of neutron precursor density.

- Neutron poisons consisting of xenon and iodine.

- Temperature feedback of reactivity

\subsubsection{Neutron Transport Equation}

The time dependent multi-group neutron transport equation with isotropic scattering and delayed neutrons is given as:

$$
\begin{aligned}
& {\left[\frac{1}{v_{g}} \frac{\partial}{\partial t}+\widehat{\Omega} . \vec{\nabla}+\sigma_{t g}(\vec{r}, t)\right] \psi_{g}(\vec{r}, \widehat{\Omega}, t)} \\
& =\sum_{g^{\prime}=1}^{G} \sigma_{s g g^{\prime}}(\vec{r}, t) \phi_{g^{\prime}}(\vec{r}, t) \\
& +\frac{\chi_{p g}}{k_{e f f}}(1-\beta) \sum_{g^{\prime}=1}^{G} v \sigma_{f g^{\prime}}(\vec{r}, t) \phi_{g^{\prime}}(\vec{r}, t) \\
& +\chi_{d g} \sum_{l} \lambda_{l} c_{l}(\vec{r}, t)+q_{g}^{e}(\vec{r}, \widehat{\Omega}, t) .
\end{aligned}
$$

where $g$ is the energy group index such that $g \in[1, G]$, such that $G$ is the total number of energy groups; $\vec{r}$ is the position; $\widehat{\Omega}$ is the direction of travel; $t$ is time; $v$ is the neutron velocity; $\sigma_{\mathrm{t}}$ is the total cross section; $\Psi$ is the angular flux; $\phi$ is the scalar flux; $\sigma_{\mathrm{s}}$ is the scattering cross section; $\sigma_{f}$ is the fission cross section; $\chi_{p}$ and $\chi_{d}$ are the fraction of prompt and the delayed fission neutrons born, respectively; $c$ is the precursor concentration; $\lambda$ is the decay constant; $\beta$ is the total fraction of fission neutrons that are delayed; $k_{\text {eff }}$ is the multiplication factor; and $q^{\mathrm{e}}$ is the external source.

To obtain the second order form of the time dependent

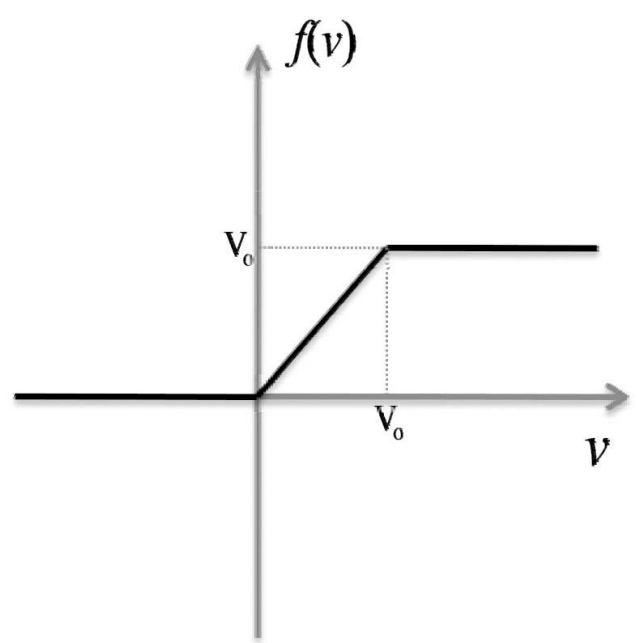

Fig. 3. The Characteristics of the Nonlinear Controlled Source.

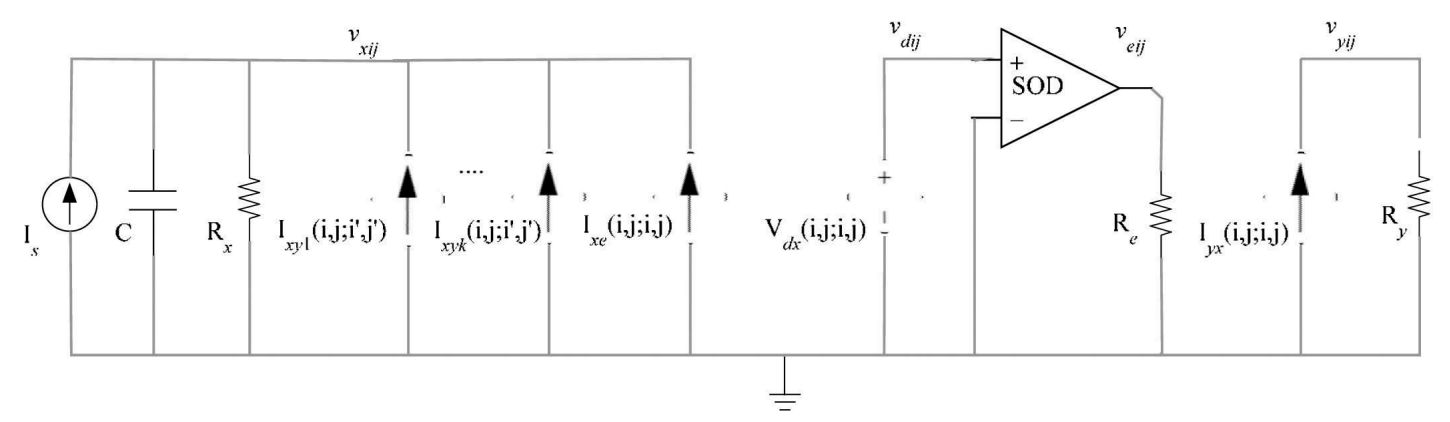

(a)

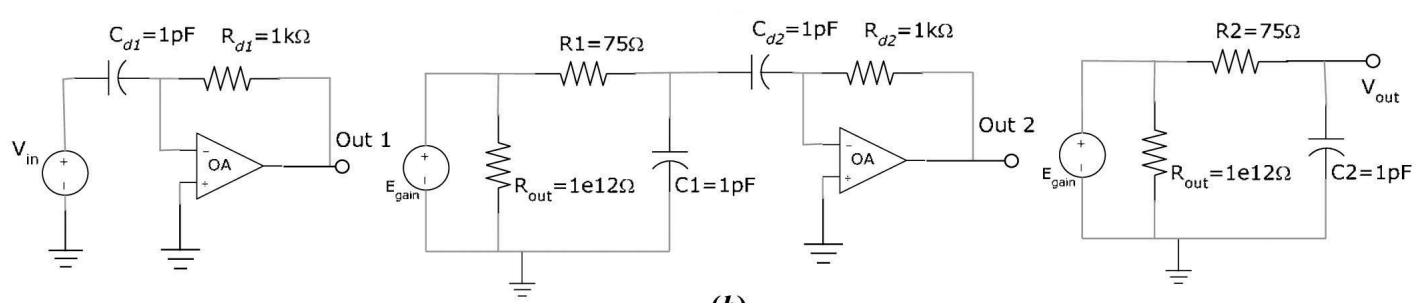

(b)

Fig. 2. a) New Cell Circuit where $C$ is a Linear-capacitor; $R_{x}, R_{e}$ and $R_{y}$ are Resistors; $I_{s}$ is an Independent Current Source; $I_{x y k}\left(i, j ; i^{\prime} ; j^{\prime}\right)$ and $I_{x e}(i, j ; i, j)$ are Linear Voltage-controlled Current Sources; $V_{d x}(i, j ; i, j)$ is a Linear Voltage-controlled Voltage Source; $I_{y x}(i, j ; i, j)$ is a

Piecewise-linear Voltage-controlled Current Source, and $S O D$ is a Second Order Differentiator. $b$ ) Electrical Circuit of $S O D$. 
neutron transport equation we use the spherical harmonic expansion of the angular flux as:

$$
\begin{aligned}
\psi_{g}(\vec{r}, \widehat{\Omega}) & =\sum_{n=0}^{\infty}(2 n+1) \\
& \times \sum_{m=0}^{n}\left[\phi_{n m g}(\vec{r}) \operatorname{cosm} \varphi\right. \\
& \left.\quad+\gamma_{n m g}(\vec{r}) \operatorname{sinm} \varphi\right] P_{n m}(\cos \theta)
\end{aligned}
$$

where $\theta$ and $\varphi$ are the axial and azimuth angles. $P_{n m}(\cos \theta)$ is the associated Legendre polynomial. The source term in the neutron transport equation is also expanded into normalized spherical harmonics as is done with the angular flux. The application of a Galerkin scheme to the neutron transport equation results in a set of first-order partial differential equations. These first-order partial differential equations allow odd moments $(\mathrm{n}=$ odd $)$ to be expressed in terms of the even moments and their derivatives. If these expressions for the odd moments are substituted throughout all equations, the resulting system is obtained as a set of second-order partial differential equations [22]. The second-order form of the $\mathrm{P}_{1}$ approximation to the two-group, 2D neutron transport is given below for an isotropic source and a homogeneous case.

$$
\begin{aligned}
& \frac{1}{v_{1}}\left(2 \sigma_{t 1}-\sigma_{s 11}-(1-\beta) \frac{v \sigma_{f 1}}{k_{e f f}}\right) \frac{\partial \phi_{1}(r, t)}{\partial t}=-\frac{1}{v_{1}^{2}} \frac{\partial^{2} \phi_{1}(r, t)}{\partial^{2} t} \\
& +\frac{1}{3}\left(\frac{\partial^{2}}{\partial x^{2}}+\frac{\partial^{2}}{\partial y^{2}}\right) \phi_{1}(r, t)-\sigma_{t 1}\left(\sigma_{t 1}-\sigma_{s 11}\right) \phi_{1}(r, t) \\
& \quad+\frac{1}{k_{e f f}}\left(\sigma_{t 1}(1-\beta)+\frac{\lambda \beta}{v_{1}}\right) \sum_{g=1}^{2} v \sigma_{f g} \phi_{g}(r, t) \\
& \quad+\left(\sigma_{t 1} \lambda-\frac{\lambda^{2}}{v_{1}}\right) c(r, t)+\sigma_{t 1} q^{e} \\
& \frac{1}{v_{2}}\left(2 \sigma_{t 2}-\sigma_{s 22}-(1-\beta) \frac{v \sigma_{f 2}}{k_{e f f}}\right) \frac{\partial \phi_{2}(r, t)}{\partial t} \\
& =-\frac{1}{v_{2}^{2}} \frac{\partial^{2} \phi_{2}(r, t)}{\partial^{2} t}+\frac{1}{3}\left(\frac{\partial^{2}}{\partial x^{2}}+\frac{\partial^{2}}{\partial y^{2}}\right) \phi_{2}(r, t) \\
& \quad-\sigma_{t 2}\left(\sigma_{t 2}-\sigma_{s 22}\right) \phi_{2}(r, t) \\
& +\sigma_{t 2} \sigma_{s 12} \phi_{1}(r, t)
\end{aligned}
$$

\subsubsection{Neutron Transport Boundary Conditions}

The usual boundary condition used with the neutron transport equation is the vacuum boundary condition, which assumes that there are no incoming neutrons from the exterior regions to the problem domain. If the transport equation is solved in a volume $\mathrm{V}$ with a surface $\Gamma$, then the vacuum boundary condition is expressed in the following form:

$$
\psi(\vec{r}, \widehat{\Omega}, E, t)=0 \text { for } \vec{n} . \vec{\Omega}<0 \text { at } \overrightarrow{\mathrm{r}} \in \Gamma
$$

In the spherical harmonic approximation of the neutron transport equation we use the following form of the above equation for the vacuum boundary condition in steady state:

$$
\int_{\vec{n} . \vec{\Omega}<0} \vec{n} \cdot \vec{\Omega} P_{n m}(\cos \theta) \sin m \varphi \psi(\vec{r}, \widehat{\Omega}, E)=0
$$

$$
\int_{\vec{n} . \vec{\Omega}<0} \vec{n} \cdot \vec{\Omega} P_{n m}(\cos \theta) \cos m \varphi \psi(\vec{r}, \widehat{\Omega}, E)=0
$$

where $n$ is even and $n<N, 0 \leq m \leq n, \vec{r} \in \Gamma$.

When the angular integrations in the equations (7-a) and (7-b) are carried out for the proper angular intervals, the resulting expressions contain both the even and the odd moments. At that point, the odd moments are replaced by the odd moment expressions in terms of the even moments and their derivatives. After that substitution, the boundary conditions consist of even moments and their derivatives in a coupled form. Further simplification of the boundary conditions is carried out by dropping all moments and derivatives that do not have the same indices as the weight function used in the angular weighting process for that specific boundary condition [22].

By using the above process, the following equation gives the $\mathrm{P}_{1}$ boundary condition for the right side of a rectangular region. Similar equations for the top, left and bottom sides can be determined.

$$
\phi+\frac{2}{3 \sigma_{t}} \frac{\partial \phi}{\partial x}=0
$$

At reflected boundaries the moment is either zero or has zero gradients, depending on whether the spherical harmonic has odd or even parity there.

\subsubsection{Delayed Neutron Precursor Equation}

The effective one group delayed neutron precursor density is [21]:

$$
\frac{\partial c}{\partial t}=-\lambda c+\frac{1}{k_{e f f}} \beta \sum_{g=1}^{2} v \sigma_{f g} \phi_{g}
$$

\subsubsection{Poison Equations}

Xenon and Iodine have the highest yield and absorption cross sections among other poisons, and thus their concentrations influence neutron population more effectively than other poisons.

$$
\begin{gathered}
\frac{\partial X e}{\partial t}=\left(-\lambda_{X e}-\sigma_{a, X e} \phi_{2}\right) X e+\lambda_{I} I+\gamma_{X e} \sigma_{f} \phi \\
\frac{\partial I}{\partial t}=-\lambda_{I} I+\gamma_{I} \sigma_{f} \phi
\end{gathered}
$$

where $X e$ and $I$ are Xenon and Iodine concentrations in (nuclei $/ \mathrm{cm}^{3}$ ), $\lambda$ and $\gamma$ are decay and yield constants, and $\sigma_{a, \mathrm{Xe}}$ is the microscopic absorption cross section for Xenon.

\subsubsection{Temperature Feedback Equation}

Temperature feedback affects the neutron flux and reactivity through the following equations:

$$
\begin{gathered}
\frac{\partial T}{\partial t}=A_{k} \phi_{2}-\gamma T(t) \\
\rho(t)=\rho_{\text {ext. }}(t)-\alpha_{t} T(t)
\end{gathered}
$$

where $T$ is the coolant and moderator temperature, $\rho(\mathrm{t})$ is the instantaneous reactivity made up of the external reactivity $\rho_{\text {ext }}(t)$ and reactivity feedbacks $\alpha_{\mathrm{T}} T$. 


\section{CNN MODEL}

To solve the above equations and simulate the steady state and transient behaviors of neutron flux distribution in the core, a symmetric nodalization in discretized Cartesian coordinates is applied. At each grid point, the neutron flux is $\phi_{g}(x, y)$ and is associated with $\phi_{g}(i \Delta x, j \Delta y)$. Using a Taylor series expansion in space, the transport equation becomes:

$$
\begin{aligned}
& \frac{1}{v_{1}}\left(2 \sigma_{t 1}^{i, j}-\sigma_{s 11}^{i, j}-(1-\beta) \frac{v \sigma_{f 1}^{i, j}}{k_{e f f}}\right) \frac{\partial \phi_{1}^{i, j}(t)}{\partial t} \\
&=-\frac{1}{v_{1}^{2}} \frac{\partial^{2} \phi_{1}^{i, j}(t)}{\partial^{2} t}+\frac{1}{3 \Delta x^{2}}\left(\phi_{1}^{i+1, j}(t)-4 \phi_{1}^{i, j}(t)+\phi_{1}^{i-1, j}(t)\right. \\
&+\left.\phi_{1}^{i, j+1}(t)+\phi_{1}^{i, j-1}(t)\right)-\sigma_{t 1}^{i, j}\left(\sigma_{t 1}^{i, j}-\sigma_{s 11}^{i, j}\right) \phi_{1}^{i, j}(t) \\
&+ \frac{1}{k_{e f f}}\left(\sigma_{t 1}^{i, j}(1-\beta)+\frac{\lambda \beta}{v_{1}}\right) \sum_{g=1}^{2} v \sigma_{f g}^{i, j} \phi_{g}^{i, j}(t) \\
&+\left(\sigma_{t 1}^{i, j} \lambda-\frac{\lambda^{2}}{v_{1}}\right) c^{i, j}(t)+\sigma_{t 1}^{i, j} q^{e i, j} \\
& \frac{1}{v_{2}}\left(2 \sigma_{t 2}^{i, j}-\sigma_{s 22}^{i, j}-(1-\beta) \frac{v \sigma_{f 2}^{i, j}}{k_{e f f}}\right) \frac{\partial \phi_{2}^{i, j}(t)}{\partial t} \\
&=-\frac{1}{v_{2}^{2}} \frac{\partial^{2} \phi_{2}^{i, j}(t)}{\partial^{2} t}+\frac{1}{3 \Delta x^{2}}\left(\phi_{2}^{i+1, j}(t)-4 \phi_{2}^{i, j}(t)\right. \\
&\left.\quad+\phi_{2}^{i-1, j}(t)+\phi_{2}^{i, j+1}(t)+\phi_{2}^{i, j-1}(t)\right) \\
& \quad-\sigma_{t 2}^{i, j}\left(\sigma_{t 2}^{i, j}-\sigma_{s 22}^{i, j}\right) \phi_{2}^{i, j}(t)+\sigma_{t 2}^{i, j} \sigma_{s 12}^{i, j} \phi_{1}^{i, j}(t)
\end{aligned}
$$

Comparison of Eqs. (12-a) and (12-b) with Eq. (1), results in 2D, 2 layer CNN cells with the following equivalent electrical elements:

$$
\left\{\begin{array}{l}
C^{\left(\phi_{g}\right)}=\frac{1}{v_{g}}\left(2 \sigma_{t g}-\sigma_{s g g}-(1-\beta) \frac{v \sigma_{f g}}{k_{e f f}}\right), g=1,2 \\
R_{x}^{\left(\phi_{g}\right)}=1 / \sigma_{t g}^{2}, \quad g=1,2 \\
D_{g a i n}^{\left(\phi_{g}\right)}=1 / v_{g}^{2}, \quad g=1,2 \\
A^{\left(\phi_{g}\right)}(i, j ; i \pm 1, j \pm 1)=1 / 3 \Delta x^{2}, \quad g=1,2 \\
A^{\left(\phi_{1}\right)}(i, j ; i, j)=\sigma_{t 1} \sigma_{s 11}+\left(\sigma_{t 1}(1-\beta)+\frac{\lambda \beta}{v_{1}}\right) \frac{v \sigma_{f 1}}{k_{e f f}} \\
\quad-4 /\left(3 \Delta x^{2}\right) \\
A^{\left(\phi_{2}\right)}(i, j ; i, j)=\sigma_{t 2} \sigma_{s 22}-4 /\left(3 \Delta x^{2}\right) \\
A^{\left(\phi_{1} \phi_{2}\right)}(i, j ; i, j)=\left(\sigma_{t 1}(1-\beta)+\frac{\lambda \beta}{v_{1}}\right) \frac{v \sigma_{f 2}}{k_{e f f}} \\
A^{\left(\phi_{2} \phi_{1}\right)}(i, j ; i, j)=\sigma_{t 2} \sigma_{s 12} \\
A^{\left(\phi_{1} c\right)}(i, j ; i, j)=\sigma_{t 1} \lambda-\frac{\lambda^{2}}{v_{1}} \\
I_{s}^{\left(\phi_{1}\right)}=\sigma_{t 1} q^{e}
\end{array}\right.
$$

where $C^{(n)}$ and $R_{x}^{(n)}$ are the $n^{\text {th }}$ layer capacitance and resistance, $D_{g a i n}^{(n)}$ is the $\mathrm{n}^{\text {th }}$ layer differentiator gain, $A^{(n m)}\left(i, j, i^{\prime}, j\right)$ denotes the linear voltage-controlled current source gain that interacts node $i, j$ in the $n^{\text {th }}$ layer with $i^{\prime}, j^{\prime}$ in the $m^{\text {th }}$ layer of the $g^{\text {th }}$ energy group; $I_{s}^{(n)}$ is the $n^{\text {th }}$ layer independent current source.

Similarly, the equivalent CNN electrical elements for delayed neutron precursors and poisons are as follows:

$$
\begin{aligned}
& \left\{\begin{array}{l}
C^{(c)}=1 \\
R_{x}^{(c)}=1 / \lambda \\
A^{\left(c \phi_{g}\right)}(i, j ; i, j)=\beta v \sigma_{f g}, \quad g=1,2
\end{array}\right. \\
& \left\{\begin{array}{l}
C^{(X e)}=1, \\
C^{(I)}=1, \\
R_{x}^{(I)}=1 / \lambda_{l}, \\
R_{x}^{(X e)}=1 /\left(\lambda_{X e}+\sigma_{a, X e} \phi_{2}^{i, j}\right), \\
A^{\left(I \phi_{g}\right)}(i, j ; i, j)=\gamma_{I} \sigma_{f g}, g=1,2, \\
A^{\left(X e \phi_{g}\right)}(i, j ; i, j)=\gamma_{X e} \sigma_{f g}, g=1,2, \\
A^{(X e I)}(i, j ; i, j)=\lambda_{I} .
\end{array}\right.
\end{aligned}
$$

where $R_{x}{ }^{(X e)}$ is a voltage-controlled resistor (VCR) that is a function of neutron thermal flux $\phi_{2}^{i, j}$.

Iodine cross sections and xenon absorption cross section for fast neutrons are ignored. Therefore, to include poison effects, $\sigma_{t 2}$ is replaced by $\sigma_{t 2}+\sigma_{a, X e} . X e^{i, j}$ in all equations.

Temperature feedback is modeled in $\mathrm{CNN}$ as:

$$
\left\{\begin{array}{l}
R_{x}^{(T)}=1 / \gamma \\
A^{\left(T \phi_{2}\right)}(i, j ; i, j)=A_{k}
\end{array}\right.
$$

\section{CASE STUDIES}

To verify the CNN results and show the ability of $\mathrm{CNN}$ in computing of neutron flux distribution in steady state and transient conditions in the core, we examine four case studies. The first case study consists of two fixed source problems. In this case we solve the one group $\mathrm{P}_{1}$ approximation of the neutron transport equation in 2D Cartesian geometry. The second is the 2D TWIGL problem that models a $160.0 \mathrm{~cm}$ square reactor consisting of three material regions. In this problem the two-group neutron transport equation and the precursor equation are simulated by CNN. The third case study is a mini-BWR assembly problem that is a simplified $2 \mathrm{D}$ simulation of a miniature BWR fuel assembly. In the final case we use the CNN model for a typical small PWR assembly to simulate the effect of poisons, temperature feedback, and control rods on scalar flux distribution.

Since the required CNN model for simulation of nuclear reactor dynamics is very complex, it is necessary to use computer codes to study the transient behavior. In the following case studies, the HSPICE software (version A2007), which is a professional electrical circuit simulator, is used to simulate the $\mathrm{CNN}$ model.

\subsection{Case 1: Fixed Source Problems}

In this case we examine two fixed source problems. 
The first source problem is a one group fixed source problem that has been widely used by Fletcher, Kobayashi and Inanc and is known as Fletcher's problem [22-24]. As shown in Fig. 4, the problem domain is a square with a side length of $4.0 \mathrm{~cm}$. The top and the right sides of the problem use the vacuum boundary condition while the other sides are reflective conditions. The material of the problem is a pure absorber and the problem domain is homogenous. The total cross section for the region is $\sigma_{t}=1.0 \mathrm{~cm}^{-1}$ and the scattering cross section is $\sigma_{s}=0.0 \mathrm{~cm}^{-1}$. The problem has a normalized constant source $q^{e}=0.69444$ neutrons. $\mathrm{cm}^{-3} \cdot \mathrm{s}^{-1}$ in a $1.44 \mathrm{~cm}^{2}$ zone at the lower left corner.

To simulate this problem using $\mathrm{CNN}$, the Cartesian space is discretized into $30 \times 30$ nodes, and then the values of CNN model elements are computed by using Eq. (13) for the one group neutron transport equation.

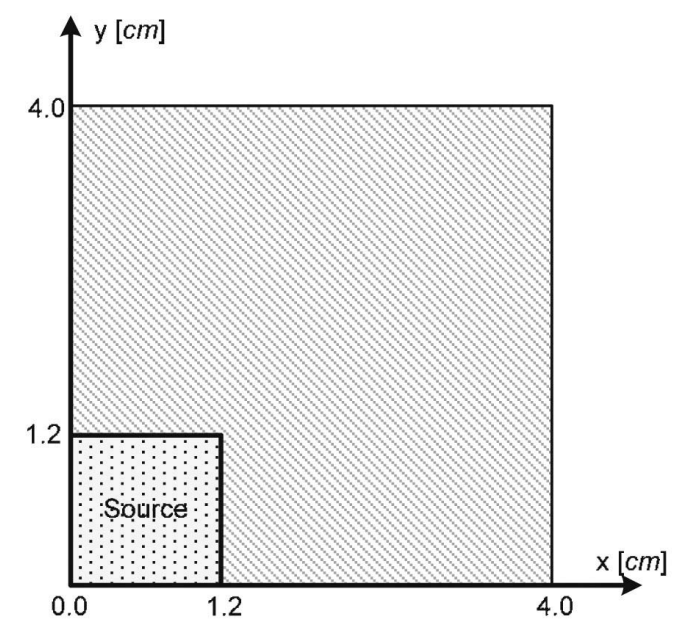

Fig. 4. The Geometry and Dimensions for Fletcher's Source Problem.

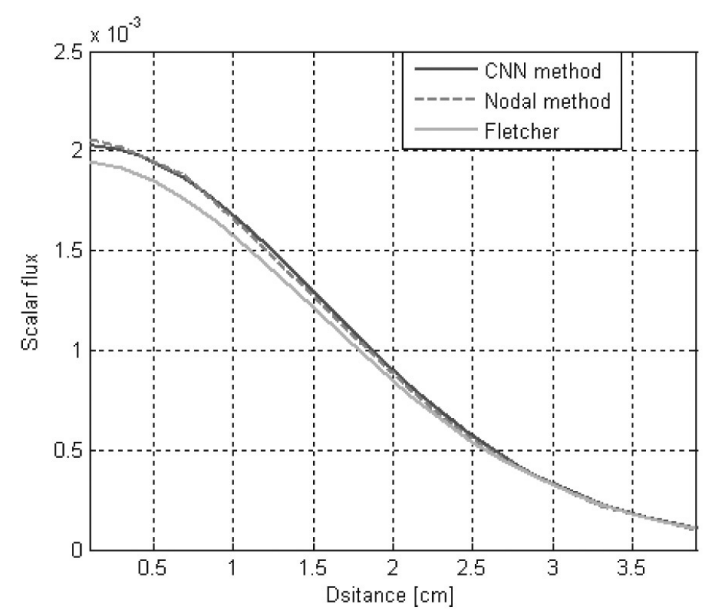

Fig. 5. Comparison of Total Flux along Line $y=3.9 \mathrm{~cm}$ for Fletcher's Source Problem.
Fig. 5 shows the scalar flux computed by CNN compared with the Fletcher and nodal method results along line $y=3.9 \mathrm{~cm}$ [22]. The difference between the $\mathrm{CNN}$ result and that of the nodal method is less than $1 \%$. However, this value for Fletcher's results is $\sim 4 \%$.

The second problem has been presented by Natelson (1971) [22]. This problem is also a one-group source problem. As shown in Fig. 6, Natelson's problem resembles Fletcher's problem but this problem has two different material regions. In addition to that, all boundaries are reflective boundaries. The neutronic parameters of the source region are different from the neutronic parameters of the outer region. The total cross section is $\sigma_{t}=1.0 \mathrm{~cm}^{-1}$ in the source region and the scattering cross section is $\sigma_{s}=$ $0.25 \mathrm{~cm}^{-1}$. The scattering cross section in the outer region is $\sigma_{s}=0.5 \mathrm{~cm}^{-1}$ while the total cross section is the same as

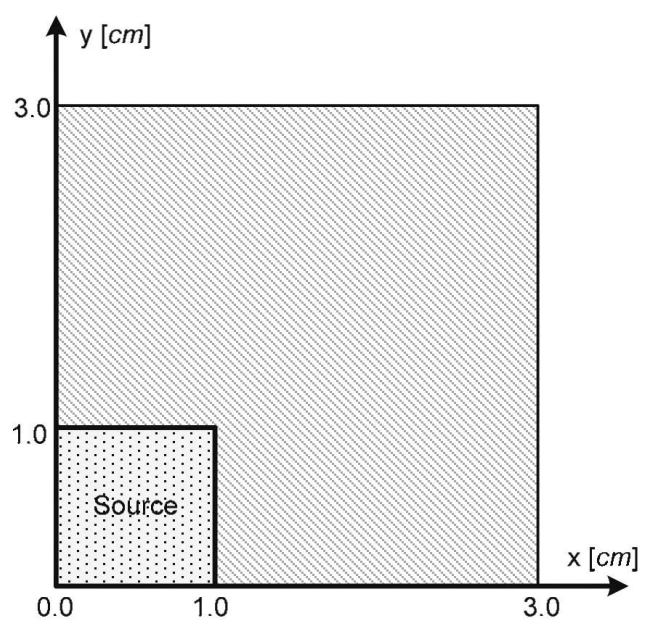

Fig. 6. The Geometry and Dimensions for Natelson's Source Problem.

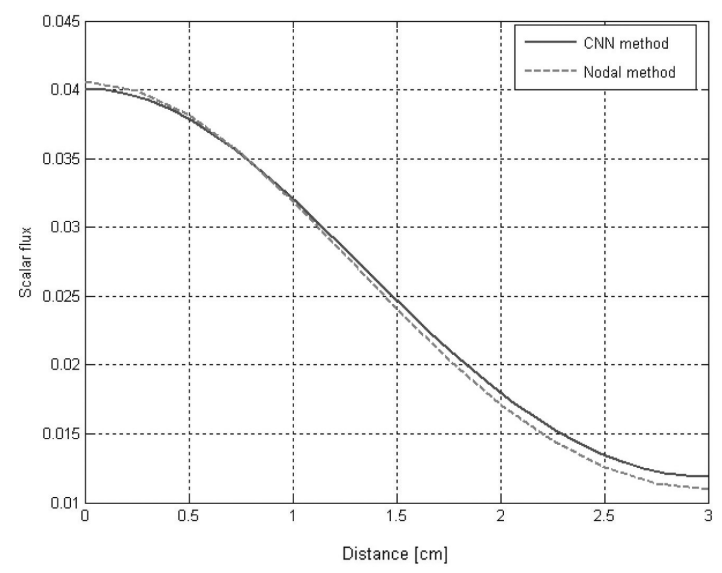

Fig. 7. Comparison of Total Flux along Line $y=3.0 \mathrm{~cm}$ for Natelson's Source Problem. 
that in the source region. The problem has a normalized constant source $q^{e}=1.0$ neutrons. $\mathrm{cm}^{-3} . \mathrm{s}^{-1}$ in a $1.0 \mathrm{~cm}^{2}$ zone at the lower left corner.

Using space nodalization as in the previous problem, this problem is simulated by HSPICE. Fig. 7 shows the scalar flux computed by CNN compared with that computed by the nodal method along line $y=3.0 \mathrm{~cm}$ [22]. The difference between the $\mathrm{CNN}$ result and that of the nodal method is less than $3 \%$.

In this part we examined two fixed source problems. In these problems the one-group neutron transport equation was modeled and simulated by $\mathrm{CNN}$. The CNN model results for both source problems are in good agreement with Fletcher's and the nodal method's results (Figs. 5 and 7).

\subsection{Case 2: 2D TWIGL Problem}

Another problem that was found to be suitable for verifying the $\mathrm{CNN}$ model is the $2 \mathrm{D}$ seed/blanket problem, developed for the purposes of validating the TWIGL diffusion theory code [25]. This problem has become a commonly used test problem for time-dependent diffusion theory and neutron transport codes and is traditionally referred to as the "TWIGL Problem". While this problem has not been standardized and a reference solution is not available, qualitative comparison can be made to previously validated results that are available in the literature.

The 2D TWIGL problem models a $160.0 \mathrm{~cm}$ square reactor consisting of three material regions: unperturbed seed regions that contain the primary fissile material, an identically composed perturbed seed region to which time-dependent properties will be introduced, and a blanket region that contains fissile material and surrounds the core on all sides. The $2 \mathrm{D}$ model is laid out in quartercore symmetry, as shown in Fig. 8.

In the initial state, this hypothetical TWIGL reactor is

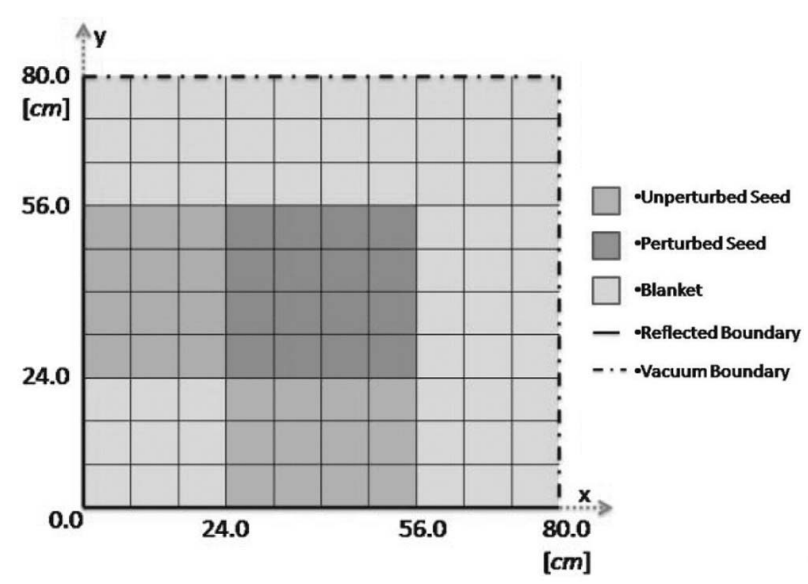

Fig. 8. Problem Schematic for 2D TWIGL Seed/Blanket Problem. slightly subcritical and the perturbed and unperturbed seed regions have identical material properties. The initial two-group properties for both materials are provided in Tables 1, and 2. Tables 3 and 4 provide the one delayed group constants and additional parameters that will be required to perform a time-dependent calculation [26].

By selecting a cell size equal to $4 \mathrm{~cm} \times 4 \mathrm{~cm}$, the $\mathrm{CNN}$ model simulates the two-group neutron transport and one group of delayed neutron precursor equations by HSPICE. The first simulation is performed with HSPICE to determine the value of $k_{e f f}$ needed to reach criticality. The subcritical reactor state described by the values in Tables 1-4 can be made critical by dividing all of the fission cross sections,

Table 1. Material Properties for 2D TWIGL Problem, Seed Regions.

\begin{tabular}{c|c|c|c|c|c}
\hline $\begin{array}{c}\text { Energy } \\
\text { group }\end{array}$ & $\begin{array}{c}\sigma_{\mathrm{tg}} \\
{\left[\mathrm{cm}^{-1}\right]}\end{array}$ & $\begin{array}{c}\sigma_{\mathrm{ag}} \\
{\left[\mathrm{cm}^{-1}\right]}\end{array}$ & $\begin{array}{c}v \sigma_{\mathrm{fg}} \\
{\left[\mathrm{cm}^{-1}\right]}\end{array}$ & $\begin{array}{c}\sigma_{\mathrm{s} 1 \mathrm{~g}} \\
{\left[\mathrm{~cm}^{-1}\right]}\end{array}$ & $\begin{array}{c}\sigma_{\mathrm{s} 2 \mathrm{~g}} \\
{\left[\mathrm{~cm}^{-1}\right]}\end{array}$ \\
\hline 1 & 0.023810 & 0.0010 & 0.00070 & 0.021810 & 0.0 \\
\hline 2 & 0.083333 & 0.0150 & 0.020 & 0.0010 & 0.068333 \\
\hline
\end{tabular}

Table 2. Material Properties for 2D TWIGL Problem, Blanket Region.

\begin{tabular}{c|c|c|c|c|c}
\hline $\begin{array}{c}\text { Energy } \\
\text { group }\end{array}$ & $\begin{array}{c}\sigma_{\mathrm{tg}} \\
{\left[\mathrm{cm}^{-1}\right]}\end{array}$ & $\begin{array}{c}\sigma_{\mathrm{ag}} \\
{\left[\mathrm{cm}^{-1}\right]}\end{array}$ & $\begin{array}{c}v \sigma_{\mathrm{fg}} \\
{\left[\mathrm{cm}^{-1}\right]}\end{array}$ & $\begin{array}{c}\sigma_{\mathrm{s} 1 \mathrm{~g}} \\
{\left[\mathrm{~cm}^{-1}\right]}\end{array}$ & $\begin{array}{c}\sigma_{\mathrm{s} 2 \mathrm{~g}} \\
{\left[\mathrm{~cm}^{-1}\right]}\end{array}$ \\
\hline 1 & 0.025641 & 0.000810 & 0.00030 & 0.023841 & 0.0 \\
\hline 2 & 0.06667 & 0.005000 & 0.006000 & 0.0010 & 0.061667 \\
\hline
\end{tabular}

Table 3. Neutron Generation Parameters for 2D TWIGL Problem.

\begin{tabular}{c|c|c|c}
\hline Energy group & $\begin{array}{c}v_{\mathrm{g}} \\
{[\mathrm{m} / \mathrm{s}]}\end{array}$ & $\begin{array}{c}\chi_{\mathrm{p}} \\
(-)\end{array}$ & $\begin{array}{c}\chi_{\mathrm{d}} \\
(-)\end{array}$ \\
\hline 1 & $1.0000 \mathrm{E}+07$ & $1.0000 \mathrm{E}+00$ & $1.0000 \mathrm{E}+00$ \\
\hline 2 & $2.0000 \mathrm{E}+05$ & $0.0000 \mathrm{E}+00$ & $0.0000 \mathrm{E}+00$ \\
\hline
\end{tabular}

Table 4. Kinetics Parameters for 2D TWIGL Problem.

\begin{tabular}{c|c|c}
\hline Delay group & $\begin{array}{c}\beta \\
(-)\end{array}$ & $\begin{array}{c}\lambda \\
(-)\end{array}$ \\
\hline 1 & $7.5000 \mathrm{E}-03$ & $8.0000 \mathrm{E}-02$ \\
\hline
\end{tabular}


$v \sigma_{f g}$, by $k_{\text {eff }}$ and then changing the value of $k_{\text {eff }}$ until criticality is reached. A reference value for $k_{\text {eff }}$ calculated in steadystate is given as $0.914193[26]$.

The CNN calculation yields $k_{\text {eff }}$ of 0.916657 , which differs from the reference value by $+0.27 \%$. The steady state neutron scalar flux distributions are shown in Figs 9 and 10. These results are comparable to Taylor's results computed using method of characteristic (MOC) [26].

To show the ability of CNN in transient simulation, we introduce a step transient in the reactor by decreasing the thermal macroscopic transport cross-section, $\sigma_{\mathrm{t} 2}$, in the perturbed seed region from the initial value of $0.83333 \mathrm{~cm}^{-1}$ to a final value of $0.82983 \mathrm{~cm}^{-1}$. Fig. 11 compares the transient result calculated by $\mathrm{CNN}$ with reference transient resulting from the step change in $\sigma_{\mathrm{t} 2}$ [26]. There is some error between the CNN results and

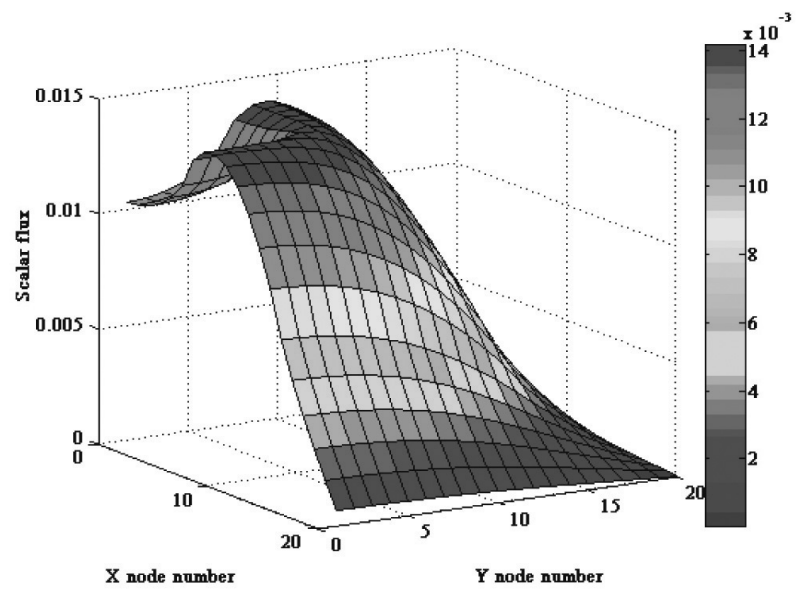

Fig. 9. Group 1 Steady State Scalar Flux Distribution for 2D TWIGL Problem.

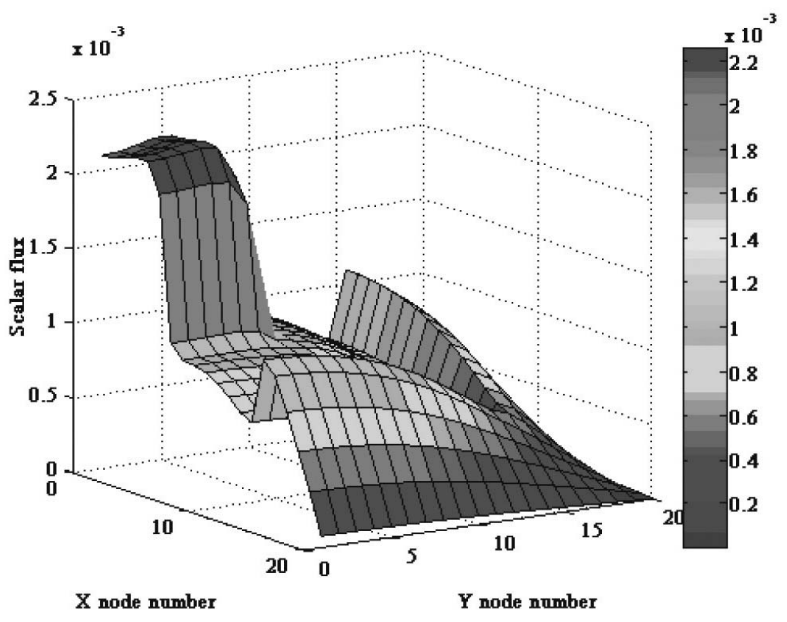

Fig. 10. Group 2 Steady State Scalar Flux Distribution for 2D TWIGL Problem. the reference results for step perturbation insertion (Fig. 11). The main reason for this error is the different approaches that have been utilized by the two models. While the CNN model uses spherical harmonic expansion of the angular flux, the reference's solution is based on the method of characteristic (MOC).

\subsection{Case 3: 2D mini-BWR Assembly Problem}

The 2D mini-BWR assembly problem is a simplified 2D simulation of a BWR fuel assembly, the surrounding coolant, and a portion of a fully inserted cruciform control rod. The fuel assembly is square with $x$ and $y$ dimensions both equal to $3.2 \mathrm{~cm}$ and is centered inside a $4.8 \mathrm{~cm}$ square coolant channel. One quarter of the control rod is modeled, i.e., half of two of the four cruciform blades, with each wing of the control blade being $2.4 \mathrm{~cm}$ long and $0.4 \mathrm{~cm}$

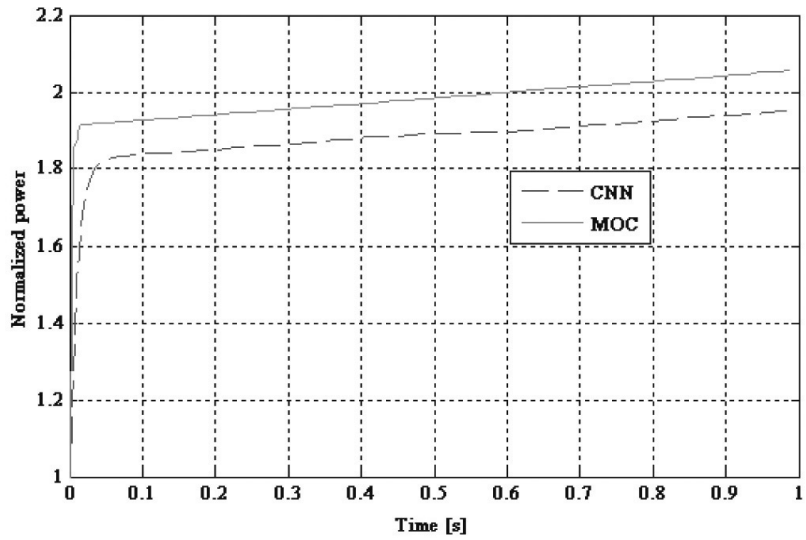

Fig. 11. Comparison of Normalized Thermal Power for the 2D TWIGL Benchmark.

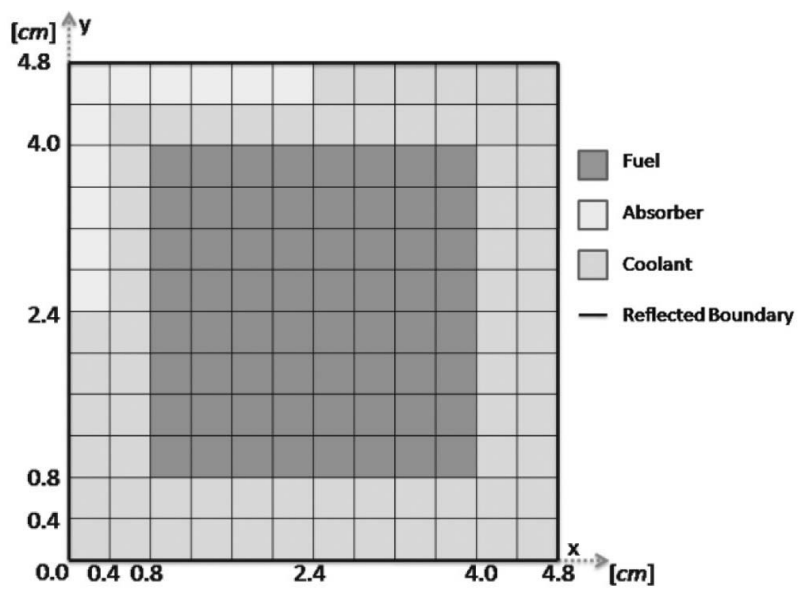

Fig. 12. Problem Schematic for 2D Mini-BWR Assembly Problem. 
wide. Fig. 12 shows a model that is decomposed into uniform $0.4 \mathrm{~cm}$ square cells.

One-group material properties for each of the three regions in this problem were calculated using the CASMO-4 lattice physics code; these data are provided

Table 5. Material Properties for 2D Mini-BWR Assembly Problem.

\begin{tabular}{c|c|c|c|c}
\hline $\begin{array}{c}\text { Delay } \\
\text { group }\end{array}$ & $\begin{array}{c}\sigma_{\mathrm{t}} \\
{\left[\mathrm{cm}^{-1}\right]}\end{array}$ & $\begin{array}{c}\sigma_{a} \\
{\left[\mathrm{~cm}^{-1}\right]}\end{array}$ & $\begin{array}{c}v \sigma_{\mathrm{f}} \\
{\left[\mathrm{cm}^{-1}\right]}\end{array}$ & $\begin{array}{c}\sigma_{\mathrm{s}} \\
{\left[\mathrm{cm}^{-1}\right]}\end{array}$ \\
\hline Fuel & 0.436526 & 0.0251889 & 0.0350929 & 0.411337 \\
\hline Coolant & 0.487382 & 0.00254071 & 0.0 & 0.484841 \\
\hline Absorber & 0.643697 & 0.1 & 0.0 & 0.543697 \\
\hline
\end{tabular}

in Table 5 [26].

CASMO-4 was utilized by Taylor to generate a reference solution for this assembly configuration using input specifications that are consistent with the $0.4 \mathrm{~cm}$ square grid shown in Fig. 12. The CASMO-4 reference value for the effective multiplication factor, $k_{\text {eff }}$ is calculated to be 0.82904 .

CNN simulation is performed for two cases. In the first case the problem domain is discretized into $12 \times 12$ nodes, while in the second we consider $24 \times 24$ nodes. The computed values of $k_{\text {eff }}$ by $\mathrm{CNN}$ for these two cases are 0.82537 and 0.82613 , respectively. By increasing the number of nodes in the CNN model, the accuracy of the $\mathrm{CNN}$ method increases so that the difference between the $k_{\text {eff }}$ computed by CNN and the reference value decreased from $0.44 \%$ to $0.35 \%$.

The normalized scalar neutron flux calculated by the CNN method is tabulated in Table 6, with the percent

Table 6. Normalized Scalar Flux Distribution Calculated by CNN Method where Second Number in Each Cell is Percent Difference of CNN and Reference Results.

\begin{tabular}{|c|c|c|c|c|c|c|c|c|c|c|c|c|}
\hline 12 & $\begin{array}{c}0.829 \\
2.86 \%\end{array}$ & & & & & & & & & & & \\
\hline 11 & $\begin{array}{c}0.843 \\
2.47 \%\end{array}$ & $\begin{array}{c}0.866 \\
0.76 \%\end{array}$ & & & & & & & & & & \\
\hline 10 & $\begin{array}{c}0.866 \\
2.84 \%\end{array}$ & $\begin{array}{c}0.882 \\
-0.42 \%\end{array}$ & $\begin{array}{c}0.912 \\
-1.42 \%\end{array}$ & & & & & & & & & \\
\hline 9 & $\begin{array}{c}0.883 \\
2.43 \%\end{array}$ & $\begin{array}{c}0.900 \\
-0.93 \% \\
\end{array}$ & $\begin{array}{c}0.934 \\
-1.08 \% \\
\end{array}$ & $\begin{array}{c}0.95 \\
-2.05 \%\end{array}$ & & & & & & & & \\
\hline 8 & $\begin{array}{c}0.902 \\
1.99 \%\end{array}$ & $\begin{array}{c}0.925 \\
-0.46 \%\end{array}$ & $\begin{array}{c}0.953 \\
-1.12 \%\end{array}$ & $\begin{array}{c}0.967 \\
-2.08 \%\end{array}$ & $\begin{array}{l}0.990 \\
-2.1 \%\end{array}$ & & & & & & & \\
\hline 7 & $\begin{array}{l}0.929 \\
1.63 \%\end{array}$ & $\begin{array}{c}0.948 \\
0.53 \%\end{array}$ & $\begin{array}{c}0.971 \\
-1.21 \%\end{array}$ & $\begin{array}{l}0.986 \\
-1.8 \%\end{array}$ & $\begin{array}{c}0.996 \\
-2.05 \%\end{array}$ & $\begin{array}{c}1.016 \\
-1.22 \%\end{array}$ & & & & & & \\
\hline 6 & $\begin{array}{c}0.970 \\
0.87 \%\end{array}$ & $\begin{array}{c}0.976 \\
-0.19 \%\end{array}$ & $\begin{array}{c}0.986 \\
-1.40 \%\end{array}$ & $\begin{array}{c}0.997 \\
-1.90 \%\end{array}$ & $\begin{array}{c}1.007 \\
-2.07 \%\end{array}$ & $\begin{array}{c}1.024 \\
-1.32 \%\end{array}$ & $\begin{array}{c}1.031 \\
-1.29 \%\end{array}$ & & & & & \\
\hline 5 & $\begin{array}{c}0.986 \\
-0.01 \%\end{array}$ & $\begin{array}{c}0.990 \\
-0.49 \%\end{array}$ & $\begin{array}{c}0.998 \\
-1.38 \%\end{array}$ & $\begin{array}{c}1.007 \\
-1.78 \%\end{array}$ & $\begin{array}{c}1.015 \\
-1.90 \%\end{array}$ & $\begin{array}{c}1.030 \\
-1.21 \%\end{array}$ & $\begin{array}{c}1.037 \\
-1.18 \%\end{array}$ & $\begin{array}{c}1.042 \\
-0.99 \%\end{array}$ & & & & \\
\hline 4 & $\begin{array}{c}0.997 \\
-0.09 \%\end{array}$ & $\begin{array}{c}1.000 \\
-0.55 \%\end{array}$ & $\begin{array}{c}1.007 \\
-1.28 \%\end{array}$ & $\begin{array}{c}1.014 \\
-1.62 \%\end{array}$ & $\begin{array}{c}1.022 \\
-1.68 \%\end{array}$ & $\begin{array}{c}1.035 \\
-1.00 \%\end{array}$ & $\begin{array}{c}1.040 \\
-0.96 \%\end{array}$ & $\begin{array}{c}1.044 \\
-0.83 \%\end{array}$ & $\begin{array}{c}1.047 \\
-0.53 \%\end{array}$ & & & \\
\hline 3 & $\begin{array}{c}1.005 \\
-0.02 \%\end{array}$ & $\begin{array}{c}1.007 \\
-0.35 \%\end{array}$ & $\begin{array}{c}1.013 \\
-0.89 \%\end{array}$ & $\begin{array}{c}1.019 \\
-1.16 \%\end{array}$ & $\begin{array}{c}1.025 \\
-1.14 \%\end{array}$ & $\begin{array}{c}1.036 \\
-0.53 \%\end{array}$ & $\begin{array}{c}1.041 \\
-0.46 \%\end{array}$ & $\begin{array}{c}1.045 \\
-0.28 \%\end{array}$ & $\begin{array}{l}1.048 \\
-0.1 \%\end{array}$ & $\begin{array}{l}1.050 \\
0.44 \%\end{array}$ & & \\
\hline 2 & $\begin{array}{c}1.010 \\
0.17 \%\end{array}$ & $\begin{array}{c}1.012 \\
-0.02 \%\end{array}$ & $\begin{array}{c}1.016 \\
-0.11 \%\end{array}$ & $\begin{array}{c}1.021 \\
-0.21 \%\end{array}$ & $\begin{array}{c}1.026 \\
-0.19 \%\end{array}$ & $\begin{array}{l}1.036 \\
0.29 \%\end{array}$ & $\begin{array}{c}1.040 \\
0.42 \%\end{array}$ & $\begin{array}{c}1.044 \\
0.56 \%\end{array}$ & $\begin{array}{c}1.047 \\
0.82 \%\end{array}$ & $\begin{array}{l}1.048 \\
1.08 \%\end{array}$ & $\begin{array}{l}1.044 \\
0.96 \%\end{array}$ & \\
\hline 1 & $\begin{array}{c}1.012 \\
0.33 \%\end{array}$ & $\begin{array}{c}1.014 \\
0.21 \%\end{array}$ & $\begin{array}{c}1.017 \\
0.13 \%\end{array}$ & $\begin{array}{l}1.022 \\
0.15 \%\end{array}$ & $\begin{array}{l}1.026 \\
0.12 \%\end{array}$ & $\begin{array}{l}1.035 \\
0.72 \%\end{array}$ & $\begin{array}{c}1.039 \\
0.72 \%\end{array}$ & $\begin{array}{c}1.043 \\
0.85 \%\end{array}$ & $\begin{array}{l}1.045 \\
1.1 \%\end{array}$ & $\begin{array}{l}1.045 \\
1.07 \%\end{array}$ & $\begin{array}{l}1.045 \\
1.16 \%\end{array}$ & $\begin{array}{c}1.044 \\
1.19 \%\end{array}$ \\
\hline & 1 & 2 & 3 & 4 & 5 & 6 & 7 & 8 & 9 & 10 & 11 & 12 \\
\hline
\end{tabular}


difference of the CNN method from the CASMO-4 code. The largest error in the CNN neutron flux distribution can be seen in Table 6; it occurs at the location of the absorber.

Fig. 13 shows the scalar flux distribution calculated by $\mathrm{CNN}$ for $24 \times 24$ nodes. This figure shows the effect of a perturbation applied to the total cross section in the control rod region on the scalar flux distribution. The value of the total cross section decreases from the initial value by $1.2 \%, 2.4 \%$, and $3.6 \%$.

\subsection{Case 4: 2D Small PWR Fuel Assembly}

This problem is a small two dimensional PWR fuel assembly with vacuum boundaries. The assembly (see Fig. 14) is $12 \mathrm{~cm} \times 12 \mathrm{~cm}$ and contains $64(8 \times 8)$ homogeneous lattice cells, four of which are control rods or water holes [27]. The nuclear data is given in Tables 3 , 4,7 , and 8 [28].

The CNN model includes a two-group $\mathrm{P}_{1}$ approximation

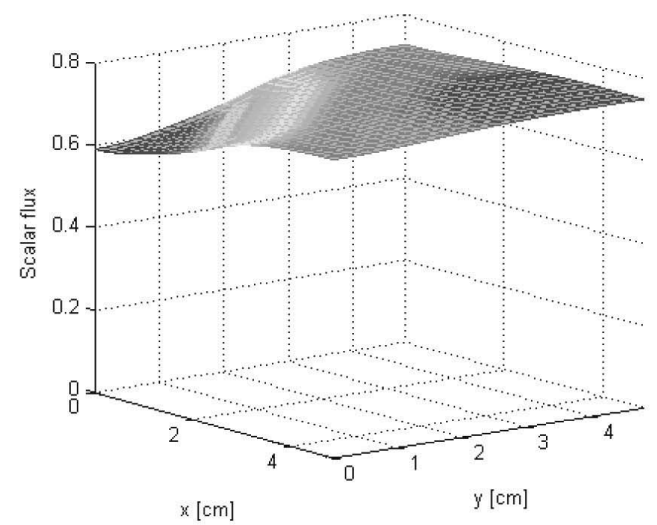

(a)

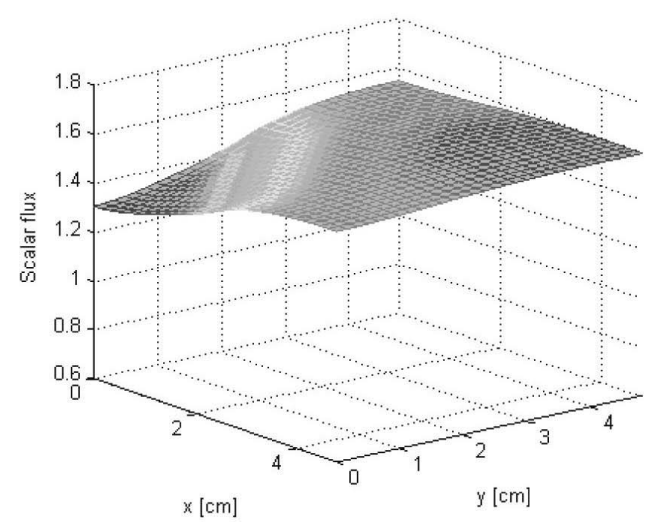

(c)

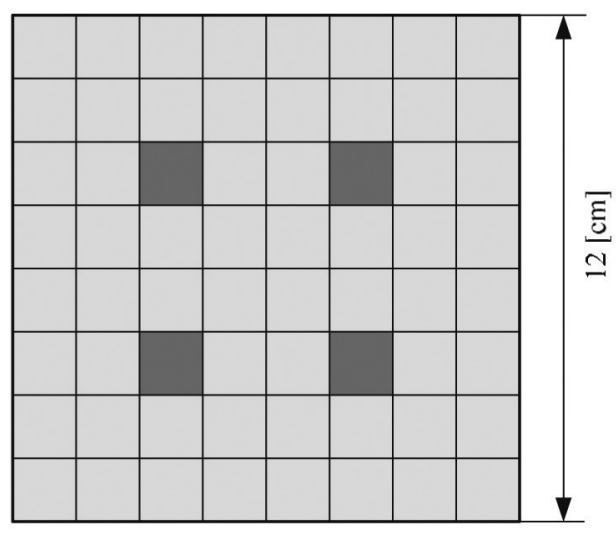

Fuel pins

Control rods/ Water holes

Fig. 14. Fuel Assembly Geometry for the Small PWR Model.

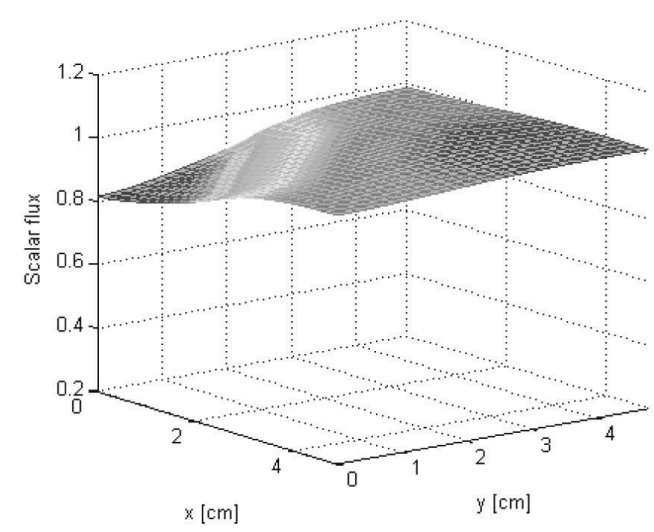

(b)

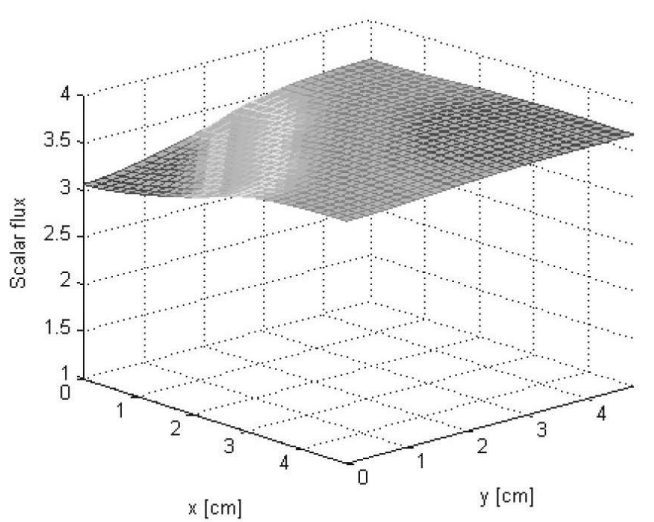

(d)

Fig. 13. Scalar Flux Distribution for Mini-BWR Assembly Calculated by CNN for Different Values of Total Cross Section in Control Rod Region, a) Initial Value, b) $1.2 \%$ Decrease, c) $2.4 \%$ Decrease, and d) $3.6 \%$ Decrease. 
of neutron transport, one group delayed neutrons, temperature feedback, and poison equations. In fact, a six layer, two dimensional $\mathrm{CNN}$ is needed to model the reactor

Table 7. Material Properties for 2D Small PWR Assembly Problem.

\begin{tabular}{c|c|c|c|c|c}
\hline Material & $\begin{array}{c}\text { Energy } \\
\text { group }\end{array}$ & $\begin{array}{c}\sigma_{\mathrm{tg}} \\
{\left[\mathrm{cm}^{-1}\right]}\end{array}$ & $\begin{array}{c}\sigma_{\mathrm{s} 1 \mathrm{~g}} \\
{\left[\mathrm{~cm}^{-1}\right]}\end{array}$ & $\begin{array}{c}\sigma_{\mathrm{s} 2 \mathrm{~g}} \\
{\left[\mathrm{~cm}^{-1}\right]}\end{array}$ & $\begin{array}{c}v \sigma_{\mathrm{fg}} \\
{\left[\mathrm{cm}^{-1}\right]}\end{array}$ \\
\hline \multirow{2}{*}{ Fuel } & 1 & 0.1852 & 0.1772 & 0.00 & 0.006 \\
\cline { 2 - 6 } & 2 & 0.6061 & 0.0120 & 0.5211 & 0.110 \\
\hline \multirow{2}{*}{ Water } & 1 & 0.500 & 0.500 & 0.00 & 0.00 \\
\cline { 2 - 6 } & 2 & 1.1111 & 0.040 & 1.1011 & 0.00 \\
\hline \multirow{2}{*}{ Absorber } & 1 & 0.1111 & 0.0311 & 1.2222 & 0.00 \\
\cline { 2 - 6 } & 2 & 2.2222 & 0.000 & 0.00 & 0.00 \\
\hline
\end{tabular}

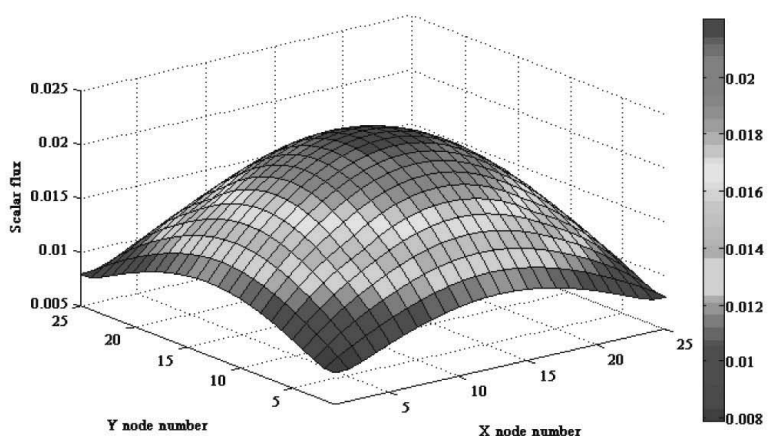

(a) kinetic equations.

There is no reference solution for this problem; however, we can use this problem to examine the whole kinetic system response qualitatively.

To simulate this problem using CNN, the Cartesian space is discretized into $25 \times 25$ nodes, and then the value of the CNN model elements are computed by using Eqs (13)-(16).

The first simulation is done to investigate the effect of the presence of control rods on the thermal and fast flux distributions. Figs. 15 and 16 illustrate the solution

Table 8. Kinetics Parameters for 2D Small PWR Assembly Problem.

\begin{tabular}{c|c|c}
\hline$\gamma_{I}=0.0638$ & $\lambda_{I}=2.87 \mathrm{e}-5\left[\mathrm{~s}^{-1}\right]$ & $\alpha_{\mathrm{T}}=0.016$ \\
\hline \multirow{2}{*}{$\gamma_{X e}=0.00228$} & $\lambda_{X e}=2.09 \mathrm{e}-5\left[\mathrm{~s}^{-1}\right]$ & $\gamma=0.0267$ \\
\cline { 3 - 3 } & & $\mathrm{A}_{k}=12.5$ \\
\hline
\end{tabular}

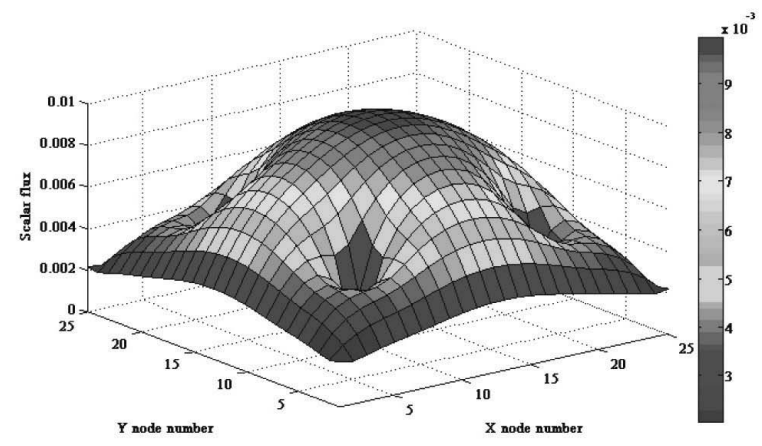

(b)

Fig. 15. The Distribution of Scalar Flux Computed by CNN when Control Rods are Not Inserted Into Core (a) Fast Group (b) Thermal Group.

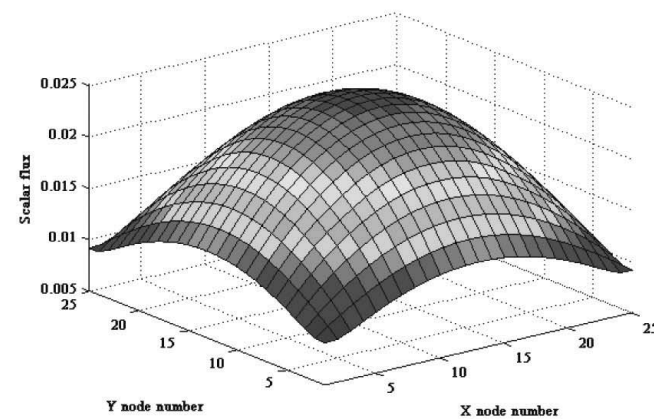

(a)

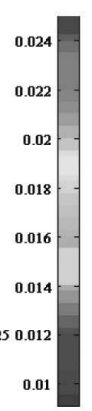

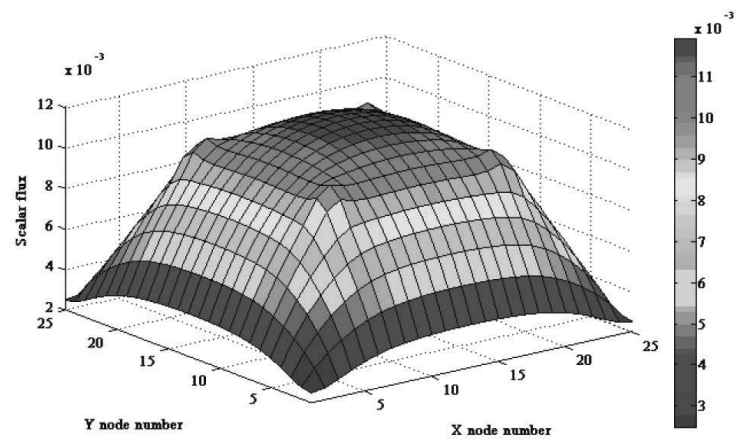

(b)

Fig. 16. The Distribution of Scalar Flux Computed by CNN when Control Rods are Not Inserted Into Core (a) Fast Group (b) Thermal Group. 


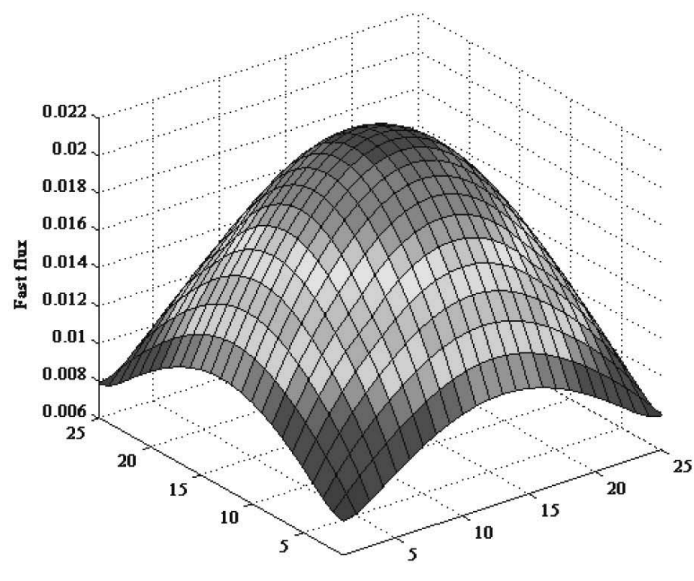

$Y$ node number

$X$ node number

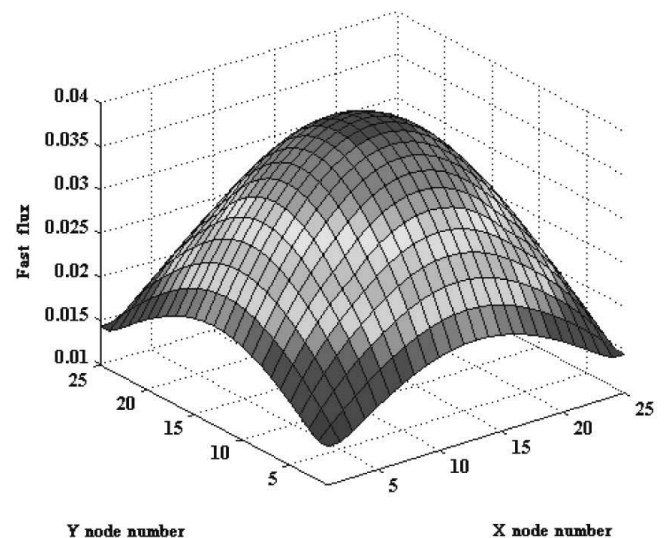

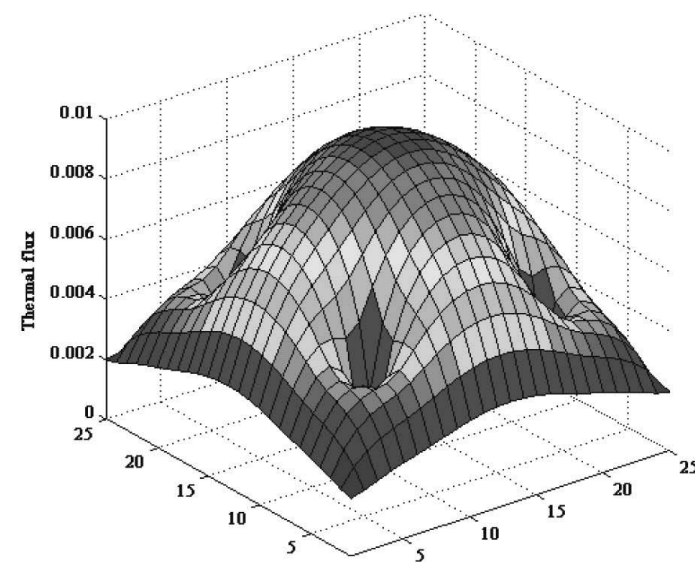

$Y$ node number

$X$ node number

(a)

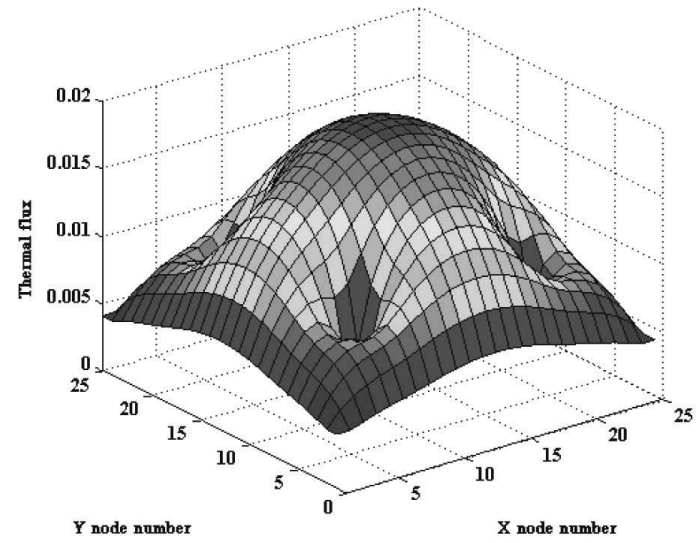

(b)

Fig. 17. The Thermal and Fast Flux Distributions (a) Before and (b) After Step Reactivity Insertion.

of thermal and fast fluxes computed by CNN for two situations: once when the control rods are inserted into the core and another when they are not and the holes are filled with water. Figs. 15(b) and 16(b) properly show the effect of the control rods on thermal flux distributions.

In the second case, we simulate a positive step reactivity insertion of 0.25 dollars. Fig. 17 shows the thermal and fast flux distributions before and after the step reactivity insertion.

\section{CONCLUSIONS}

In this work we introduced a time-dependent second order form of the neutron transport equation. Implementation of the new equation compared with that of the traditional form of the neutron transport equation is easier because the new equation has a form analogous to the neutron diffusion equations. Also, the number of unknown variables is significantly reduced [22]. We also introduced a new cell circuit for CNN to extend the capabilities of CNN for simulation of more complex systems such as timedependent second order forms of the neutron transport equation.

The purpose of this paper was to develop a new simulator for nuclear reactor dynamics based on CNN. After modeling the governing equations using $\mathrm{CNN}$ we used four case studies to verify the accuracy and examine the capabilities of the CNN model in simulating steady state and transient situations. The CNN model was used to simulate the space-time response of scalar flux distribution in the steady state and transient conditions. Use was made of the CNN model to simulate step perturbation in the core for different test problems.

The CNN method has great potential to efficiently analyze complex and stiff models and provide ultra-fast 
and accurate solutions. The advantages of the CNN simulator over the numerical methods have to do with its analog and parallel processing algorithm. These advantages include, but are not necessarily limited to, reduction in the computational time, circumvention of the exponential increase in complexity as the scale and dimension of problems increase, and the capability of modeling transient conditions. The CNN model, being an online and realtime system, can simulate the effect of system parameter variations during simulation. It is also possible to implement the complete algorithm using very large-scale integrated circuit technology (VLSI).

To improve the accuracy of the existing CNN model and convert it to a more practical model for simulating nuclear reactor dynamics, we will try to use $\mathrm{P}_{3}$ or $\mathrm{P}_{5}$ approximation of the neutron transport equation and also the decay heat equation in future works. This model can be extended to three-dimensional geometry.

\section{REFERENCES}

[1] D. L. Hetrick, "Dynamics of Nuclear Reactors, American Nuclear Society," La Grange Park, IL (1993).

[2 ] E. E. Lewis, "Nuclear Power Reactor Safety," John Wiely \& Sons, New York (1977).

[ 3 ] G. Y. Han, "A mathematical model for the thermal-hydraulic analysis of nuclear power plants," Int. Comm. Heat Mass Transfer, 27(6), pp. 795-805(2000).

[4] I. Khamis, M. B. Alsous, H. Haj Hassan, and H. Jouhara, "Dynamic simulator for the miniature neutron source reactor," Progress in Nuclear Energy, 36(4), pp. 379$385(2000)$.

[5] J.G. Hayes and E.J. Allen, "Stochastic point-kinetics equations in nuclear reactor dynamics," Annals of Nuclear Energy, 32(6), pp. 572-587(2005).

[6] F. Cadini, E. Zio, and N. Pedroni, "Simulating the dynamics of the neutron flux in a nuclear reactor by locally recurrent neural networks," Annals of Nuclear Energy, 34(6), pp. 483-495(2007).

[ 7 ] Zhe Dong, Xiaojin Huang, Junting Feng, and Liangju Zhang, "Dynamic model for control system design and simulation of a low temperature nuclear reactor," Nuclear Engineering and Design, 239(10), pp. 2141-2151(2009).

[8] Fan Zhang, Wen-zhen Chen and Xin-wen Zhao, "The dynamic simulation of cold start-up based on two-group point reactor model," Annals of Nuclear Energy, 36(6), pp. 784-786(2009).

[9] B. Montagnini, P. Raffaelli, M. Sumini and D. M. Zardini, "A 3D coarse-mesh time dependent code for nuclear reactor kinetic calculations," Annals of Nuclear Energy, 23(6), pp. 517-532(1996).

[10] F. Cadini and E. Zio, "A Monte Carlo method for the modelbased estimation of nuclear reactor dynamics," Annals of Nuclear Energy, 34(10), pp. 773-781(2007).

[11] Tewfik Hamidouchea, Anis Bousbia-Salah, El Khider SiAhmed, Mohamed Yazid Mokeddem, and Franscesco D'Auria, "Application of coupled code technique to a safety analysis of a standard MTR research reactor," Nuclear Engineering and Design, 239(10), pp. 2104-2118(2009).

[12] K. Hadad and A. Piroozmand "Application of cellular neural network $(\mathrm{CNN})$ method to the nuclear reactor dynamics equations," Annals of Nuclear Energy, 34(5), pp. 406-416, (2007).

[13] T. Kozek, L. O. Chua, T. D. Roska, R. Wolf, F. Tetzaff, F. Puffer and K. Lotz, "Simulation nonlinear waves and partial differential equations via CNN - part II: typical examples," IEEE Trans. Circuits Syst. 42(10), pp. 816-820(1995).

[14] W. Krstic, "Cellular neural network to model and solve direct non-linear problem of steady-state heat transfer," IEEE Trans. Circuits Syst., pp. 420-423(2001).

[15] Leon O. Chua and L. Yang, "Cellular Neural Networks: Theory," IEEE Trans. Circuits Syst., 35, pp. 1257-1272, (1998).

[16] L. O. Chua and L. Yang, "Cellular Neural Networks: Application," IEEE Trans. Circuits Syst., 35, Page(s) 1273-1290, (1998).

[17] J. C. Chedjou, K. Kyamakya, M. A. Latif, U. A. Khan, and I. Moussa, and Do Trong Tuan, "Solving Stiff Ordinary Differential Equations and Partial Differential Equations Using Analog Computing Based on Cellular Neural Networks," ISAST Transactions on Computers and Intelligent Systems, Vol. 1 (2), (2009).

[18] Sandor Kocsardi, Zoltan Nagy, Arpad Csik and Peter Szolgay, "Two-dimensional Compressible Flow Simulation on Emulated Digital CNN-UM," 11th International Workshop on Cellular Neural Networks and their Applications, Santiago de Compostela, Spain (2008).

[19] F. Pardo, P. Lopez, and D. Cabello, "DT-CNN emulator: $3 \mathrm{D}$ heat equation solver with applications on the nondestructive soil inspection," 11th International Workshop on Cellular Neural Networks and their Applications, Santiago de Compostela, Spain (2008).

[20] Kamal Hadad, Ahmad Pirouzmand, and Navid Ayoobian, "Cellular neural networks $(\mathrm{CNN})$ simulation for the TN approximation of the time dependent neutron transport equation in slab geometry," Annals of Nuclear Energy, 35(12), pp. 2313-2320, (2008).

[21] W.M. Stacy, Nuclear Reactor Physics, Wiley, New York, pp. 599-665, (2001).

[22] F. Inanc and A. F. Rohach "A nodal simulation of the multigroup neutron transport equation using spherical harmonics," Ann. nucl. Energy, 15(10), pp. 501-509, (1988).

[23] J. K. Fletcher, "A solution of the neutron transport equation using spherical harmonics," J. Phys. A: Math. Gen., 16, pp. 2827-2835(1983).

[24] K. Kobayashi, H. Oigawa, and H. Yamagata, "The spherical harmonics method for the multi-group transport equation in x-y geometry," Ann. nucl. Energy, 13(12), pp. 663678(1986).

[25] L.A. Hageman and J.B. Yasinski, "Comparison of Alternating-Direction Time-Differencing Methods with Other Implicit Methods for the Solution of the Neutron Group-Diffusion Equations," Nucl. Sci. Eng., 38, pp. 8, (1969).

[26] J. B. Taylor, "The Development of a Three-Dimensional Nuclear Reactor Kinetics Methodology Based on the Method of Characteristics," Ph.D. Thesis in Nuclear Engineering, Pennsylvania State University, (2007).

[27] Hongbin Zhang, Rizaan-uddin, and J. J. Dorning, "Systematic homogenization and self-consistent flux and 
pin power reconstruction for nodal diffusion methods. Part II: transport equation based theory," Transport Theory and Statistical Physics, 26(4\&5), pp. 433-468(1997).
[28] A. Dallosso, "A spatial rehomogenization method in nodal calculations," Annals of Nuclear Energy, 33, pp. 869-877, (2006). 